\title{
Burnout e hardiness: um estudo de evidência de validade
}

\author{
Sandra Cristina Mallar ${ }^{1}$ \\ Cláudio Garcia Capitão
}

\begin{abstract}
Resumo
O presente trabalho foi realizado com o objetivo de verificar se professores que trabalham com alunos portadores de necessidades especiais apresentavam-se com hardiness e, conseqüentemente, sem burnout, como também verificar a validade concorrente entre as dimensões dos instrumentos Maslach Burnout Inventory e o Personal Views Survey. Participaram 56 professores que trabalhavam exclusivamente com alunos com necessidades especiais, na faixa etária compreendida entre 19 e 54 anos. Verificou-se que cinco professores apresentavam personalidade resistente ao estresse e outros três, que não apresentavam hardiness, apresentavam burnout. Realizada a análise de correlação entre as dimensões dos dois instrumentos, verificou-se que apenas as dimensões Controle e Redução da Realização Pessoal estão positivamente correlacionadas. Assim, pôde-se concluir que há validade concorrente entre os dois instrumentos, e se confirmou a hipótese de que portadores de hardiness conseguem atenuar os efeitos do estresse e desenvolvem menos burnout.
\end{abstract}

Palavras-Chave: Burnout; Hardiness; Professores; Validade concorrente.

\section{Burnout and hardiness: A study of evidence of validity}

\begin{abstract}
The objective of this work was to verify if teachers who work with students with special needs would show hardiness and, consequently, no burnout, and also to verify the concurrent validity between the dimensions of both instrument Maslach Burnout Inventory and Personal Views Survey. Fifty-six teachers, who work only whith students with special needs and aged 19-54 years old, participated on this study. Five teachers presented resistant personality to stress and other three, who did not showed hardiness, had burnout. After the analysis of correlation among the dimensions of the two instruments, only the dimensions Control and Reduction of the Personal Realization are positively co-related. So, there is a concurrent validity between the two instruments, and it is confirmed the hypothesis that people who have hardiness can attenuate the effects of stress and develop less burnout.

Keywords: Burnout; Hardiness; Teachers; Contributing validity.
\end{abstract}

O mundo contemporâneo inaugurou uma nova ordem na relação do homem com o trabalho. O desenvolvimento globalizado aponta cada vez mais para a especialização, a tecnologia, a robotização, a desumanização dos contatos humanos e afetivos dentro dos ambientes produtivos. Do outro lado da linha estão os profissionais que fazem do contato direto, permanente, sua condição de trabalho. São professores, enfermeiros, médicos, policiais, aqueles chamados atualmente de profissionais de "alto contato", os quais aliam às longas jornadas o inevitável envolvimento com os "problemas dos outros" e a excessiva carga de trabalho em ambientes potencialmente geradores de conflitos.

Não por acaso proliferaram nas duas últimas décadas estudos a respeito do impacto das organizações sobre a vida (e a morte) do trabalhador. Saúde e Trabalho, Saúde Mental e Trabalho, Psicopatologia do Trabalho, Saúde do Trabalhador, Doenças Ocupacionais e outras tantas terminologias e subdivisões teóricas e técnicas configuram claramente que o trabalho é, hoje, na vida das pessoas, uma inescapável área de problemas. Maslach e Leiter (1999) afirmam que

ao invés de existirem organizações para aumentar a capacidade das pessoas de ganhar a vida e realizar conquistas significativas, há pessoas sacrificando suas vidas e suas aspirações pelo bem das empresas. (p. 15)

Aquela condição enobrecedora do trabalho, ideologicamente decantada nos ditos populares, tem sido sistematicamente contestada pelos resultados das pesquisas que investigam a natureza do sofrimento proveniente das relações do homem moderno com o trabalho. Trabalho e sofrimento, portanto, podem estar intrinsecamente associados, se as condições do primeiro predispuserem o sujeito a determinados contextos e situações, presentes no que Dejours (1997) denominou de "organização do trabalho", constituída por divisão do trabalho, conteúdo das tarefas, sistemas hierárquicos, modalidades de comando, relações de poder e questões

E-mail para correspondência:

1 sandramallar@unia.br

2 cgcapitao@uol.com.br 
de responsabilidade. Sabe-se, hoje, que o trabalhador adoece em virtude do local e das contingências do trabalho.

Capitão (1998), numa perspectiva sociopsicológica, argumenta que existe um certo terrorismo praticado contra a grande massa de trabalhadores existentes em quase todo o planeta. Trata-se de uma ameaça com objetivo certeiro possibilitando que milhares de pessoas acordem ou durmam sobressaltadas, pois a única coisa que de fato possuem, sua força de trabalho, pode ser dispensada a qualquer momento.

Conhecer a saúde geral e mental dos trabalhadores, seu adoecer, as relações entre as doenças, os agravos psicossomáticos e certas características do trabalho tem sido tarefa das mais importantes nos tempos atuais, tanto para a Medicina quanto para a Psicologia. Seisdedos (1997) aponta a grande incidência de quadros de esgotamento, entre eles o da Síndrome de burnout, em trabalhadores de instituições assistenciais, nas áreas da saúde e da educação, por estarem permanentemente expostos aos problemas e às preocupações daqueles a quem atendem profissionalmente. $\mathrm{O}$ acúmulo de estresse permanente, crônico, pode conduzi-los ao desenvolvimento desta síndrome, definida por Freudenberger, em 1974, como uma experiência de esgotamento, decepção, exaustão física e emocional e perda de interesse, manifestadas por profissionais "normais", que não apresentam nenhum quadro psicopatológico antes de seu surgimento e que apontam para uma redução da efetividade e do desempenho no trabalho, acompanhada de atitudes negativistas e hostis.

De acordo com Maslach e Jackson (1981/1986), conceitualmente, a síndrome de burnout compreende esgotamento emocional (caracterizado por uma falta ou carência de energia, de entusiasmo, um sentimento de sobrecarga emocional, de esgotamento de recursos), despersonalização (processo de endurecimento, de insensibilidade, que se manifesta através de uma atitude fria e distante para com os que recebem os cuidados, clientes ou colegas, mostrando-se impessoal, muitas vezes cínico) e redução da realização pessoal (uma tendência a se auto-avaliar de forma negativa, com a diminuição dos sentimentos de competência, levando-o a sentir-se frustrado, inadequado, infeliz e descontente, tanto consigo mesmo como com o seu trabalho).

Benevides-Pereira (2002) caracteriza a síndrome de burnout pela presença de sintomas físicos, psíquicos, comportamentais e defensivos. Os sintomas físicos compreendem a sensação de fadiga constante e progressiva, distúrbios do sono, dores musculares ou osteomusculares, cefaléias, enxaquecas, perturbações gastrointestinais, imunodeficiência, transtornos cardiovasculares, distúrbios do sistema respiratório, disfunções sexuais e alterações menstruais nas mulheres.

Entre os sintomas psíquicos constata-se a falta de atenção e de concentração, alterações da memória, lentificação do pensamento, sentimento de alienação, de solidão, de insuficiência, impaciência, desânimo, disforia, depressão, desconfiança e paranóia. Já os sintomas comportamentais compreenderiam a falta ou excesso de escrúpulos, irritabilidade, incremento da agressividade, incapacidade para relaxar, dificuldade de aceitação de mudanças, perda de iniciativa, aumento do consumo de substâncias, comportamento de alto risco e aumento da probabilidade de suicídio. Os sintomas defensivos caracterizam-se pela tendência ao isolamento, sentimento de onipotência, perda do interesse pelo trabalho ou pelo lazer, insônia e cinismo. Para Varoli (2002), todas as questões referentes aos sintomas são mal-elaboradas, pois, equivocadamente se deposita nas pessoas que se encontram desgastadas um problemas que nelas apenas é revelado, pois tem origem no desequilíbrio entre o trabalhador e o trabalho.

Moreno e Oliver (1993) afirmam que os mais afetados por esta síndrome são, sobretudo, os profissionais mais iludidos, os mais esperançosos, aqueles cujas expectativas são mais altas, e, às quais a realidade vem restringir, vem frustrar. Assim, como conseqüência, o profissional acaba por substituir uma atitude de dedicação e compromisso, de crença em si mesmo, por uma atitude apática e desinteressada. Também Freudenberger (1974) alude ao fato de serem justamente os profissionais mais dedicados e mais comprometidos com o trabalho os mais propensos a desenvolver burnout.

Temporalmente, foi no início dos anos 80 que se verificou o desenvolvimento conceitual de burnout. Maslach e Jackson (1981/1986) conceberam o modelo de estrutura tridimensional que o caracteriza, desenvolvendo seu correspondente objeto de medida, o qual denominou de MBI - Maslach Burnout Inventory. Esse modelo, organizado em torno de três dimensões, é mundialmente aceito. De acordo com Carlotto (2002), o modelo está baseado sob uma perspectiva sociopsicológica e assim distribuído: Exaustão emocional, caracterizada por uma falta ou carência de energia, de entusiasmo, um sentimento de sobrecarga emocional, de esgotamento de recursos; despersonalização, caracterizada por um processo de endurecimento, de insensibilidade, que se manifesta através de uma atitude fria e distante para com os que recebem os cuidados, clientes ou colegas, impessoalidade e atitude cínica; redução da realização profissional, que traz ao profissional uma tendência a se auto-avaliar de forma negativa, com a diminuição dos sentimentos de competência, levando a pessoa a sentirse frustrada, inadequada, infeliz e descontente, tanto consigo mesma como com o seu trabalho.

Alguns autores têm proposto o entendimento do burnout como um quadro depressivo derivado do mundo do trabalho (Fráguas \& Figueiró, 2001); outros, 
porém, afirmam que a depressão e a síndrome de burnout apresentam, de fato, certas semelhanças, como cansaço, isolamento social e sentimentos de desvalia, todavia há diferenças acentuadas entre os dois quadros clínicos. Leiter e Durup (1994, citados por Gil-Monte e Peiró, 1997) assinalam que o burnout é fundamentalmente um construto social que surge como conseqüência das relações interpessoais e organizacionais, enquanto a depressão é um conjunto de emoções e cognições que têm conseqüências sobre essas relações interpessoais.

Uma das categorias profissionais mais atingidas pelo desgaste profissional é a de professores, conforme se verifica em diversos estudos (Byrne, 1994; Codo \& Menezes, 1999; Farber, 1991; Moreno, Garrosa \& Gonzalez, 2000). Farber (1991) refere que a severidade de burnout entre os trabalhadores da educação já se encontra em nível superior à dos profissionais de saúde, colocando o magistério dentre as áreas profissionais mais vulneráveis e de maior risco.

Para Guglielmi e Tatrow (1998), o burnout afeta o ambiente educacional e interfere na obtenção dos objetivos pedagógicos, o que acaba levando o professor a um processo de alienação, apatia e desumanização, além de fazer surgir intenções de abandono da profissão. No Brasil foi realizado estudo sobre saúde mental e trabalho com 39.000 professores da Escola Pública (Codo \& Menezes,1999) e verificou-se que 48,4\% dos docentes apresentavam dados que confirmariam a presença de burnout ou de desgaste profissional, caracterizando uma categoria cujo sofrimento, advindo de certas condições de trabalho (salário insuficiente, falta de recursos, falta de segurança, violência e outras) é intenso.

Nem sempre, porém, o profissional submetido cronicamente a situações estressantes no ambiente de trabalho responde com grave quadro de esgotamento ou burnout. Estratégias diferentes e mais eficazes de enfrentamento ao estresse podem significar maior resistência e menor sofrimento para as pessoas.

Kobasa (1979) realizou um estudo longitudinal, em executivos, por um período de 8 anos e encontrou dois grupos que se apresentaram de maneiras diferentes diante do estresse provocado pela mudança de seus empregos. Um grupo se apresentou mais sintomático ante o estresse, necessitando de assistência médica; o outro grupo não mostrou nenhuma diferença nos sintomas durante este período, comparado com o início; pelo contrário, apresentou-se de forma mais saudável e robusta. As pessoas deste último grupo foram denominadas como hardy personality, ou hardiness, personalidade resistente. $\mathrm{O}$ construto de personalidade resistente, hardiness, advém de conceitos teóricos do existencialismo, para o qual o indivíduo, ao longo de sua vida, das suas ações, de forma contínua, vai construindo sua personalidade, com inevitáveis mudanças associadas a situações estressantes
(Peñacoba \& Moreno, 1998).

Kobasa, Maddi e Khan (1982) definem hardiness como uma constelação de características de personalidade que funcionam como uma fonte de resistência diante dos acontecimentos estressantes. Tais características se resumem em três dimensões, ou seja, compromisso, controle e desafio.

Compromisso caracteriza-se pela tendência de a pessoa envolver-se com tudo que faz, identificando-se com o significado dos próprios trabalhos (Moreno, Garrosa \& Gonzalez, 2000). Entende-se como a qualidade de crer na verdade, na importância e no valor de si mesmo, no reconhecimento das próprias habilidades de tomada de decisão; este compromisso consigo mesmo proporciona ao indivíduo um conjunto de propósitos que contribui para a amenização de qualquer estímulo estressante, em qualquer área da vida

Controle foi definido por Kobasa (1979) como uma tendência a pensar e a atuar com a convicção das influências pessoais durante os acontecimentos. As pessoas com essas qualidades buscam as explicações sobre o porquê dos acontecimentos, não só nas ações dos demais, mas em suas responsabilidades também. A capacidade de controle permite ao indivíduo perceber em muitos acontecimentos estressantes conseqüências previsíveis, e, conseqüentemente, a manipular os estímulos em seu benefício.

A última das três características que compõem o conceito de hardiness é Desafio, que faz referência à crença de que a mudança, frente a estabilidade, é a característica habitual da vida. Esta concepção de mudança é entendida com uma oportunidade, um incentivo para o crescimento pessoal, podendo evitar, assim, os estímulos estressantes, vendo-os não como uma ameaça à sua segurança. Graças a essa visão de mudança como fonte de novas e interessantes experiências, os esforços da pessoa convergem para encontrar meios de fazer frente, de corresponder às novas situações, inclusive àquelas carregadas de estímulos estressantes. Essa qualidade proporciona uma maior flexibilidade cognitiva e uma tolerância às contradições geradoras de conflitos.

Nos últimos 20 anos a concepção de personalidade resistente emergiu como disposição de personalidade que aumenta o desempenho, a conduta, moral, força e saúde, atuando assim como um indicador negativo do estresse. As pesquisas mostram que os mecanismos da personalidade resistente podem preservar a saúde, aumentar o desempenho e promover mudanças na vida (Moreno, Garrosa \& Gonzalez, 2000). Mencionam também que o uso de coping regressivo, isto é, reações de fuga ou evitamento às situações de estresse, assim como pontuações baixas em personalidade resistente encontram-se associados a altos níveis de burnout em professores do ensino secundário. 
Desta maneira, torna-se necessária a construção e a validação de instrumentos que possam de fato identificar e verificar o desgaste emocional em várias categorias de profissionais. Os testes psicológicos como instrumentos de predição do comportamento humano são largamente utilizados em todas as áreas de atividades humanas; esta freqüência se justifica pelo desenvolvimento da sociedade, exigindo cada vez mais as pessoas certas nos lugares certos. Pasquali (1999) afirma que avaliar é atividade inerente ao ser humano, que necessita avaliar o meio que o circunda a fim de tomar decisões e verificar hipóteses sobre as características das outras pessoas, no seu confronto com elas. Constitui-se num processo informal, na medida em que todos os humanos avaliam o ambiente que os cerca e as pessoas com as quais interagem, para representá-los, e, a seguir, sobre tais representações tomar decisões que visem garantir sua sobrevivência; e num formal, sistemático, que se refere a julgamentos feitos sob valores impostos pela sociedade, com base em códigos e sistemas classificatórios. Pasquali (2001) define que as origens formais da psicometria, como o uso de números para descrever os fenômenos que a psicologia estuda, tal qual utilizamos nos dias atuais, remonta ao fim do século XIX e início do século passado, na esteira do estudo do número, símbolo de quantidade e extensão que permitiu basear as técnicas de mensuração, posteriores bases para uma nova tecnologia de avaliação.

Alchieri (2002) postula que as idéias de medida, longe de simplesmente associarem um número à pessoa, implicam o respeito a um conjunto de regras e procedimentos que caracterizam e legitimam o processo. A medida em psicologia traz consigo a responsabilidade de demonstrar, por meio de procedimentos estatísticos, o comportamento humano.

Casullo (1997) apresenta a idéia de que não existe unicamente um modelo teórico de avaliação psicológica, havendo, assim, várias linhas de trabalho centradas no sujeito, nas interações e nas situações. Avaliação é um processo pelo qual se verificam os fenômenos e a correspondência existente entre as formulações teóricas e dados empíricos mediante técnicas, verdadeiras mediadoras entre o modelo teórico e o fenômeno que se pretende compreender.

Também para Sisto, Codenotti, Costa \& Nascimento (1979) "um teste só adquire sentido e validade quando se refere a uma população e contexto determinados" (p.153). Afirmam que no campo da Psicometria não é somente oportuno, mas necessário haver uma correspondência entre a realidade e o meio para mensurá-la.

Nesse contexto, o objetivo deste trabalho foi verificar se professores que trabalham com alunos portadores de necessidades especiais apresentavam hardiness ou burnout, como também verificar a validade concorrente entre as dimensões dos instrumentos Maslach Burnout Inventory e o Personal Views Survey.

\section{Método}

\section{Participantes}

Como se pretendia estudar desgaste e resistência em professores de crianças portadoras de necessidades especiais, participaram 56 professores de duas APAEs (Associação de Pais e Amigos dos Excepcionais). Trabalhavam em duas cidades localizadas na região metropolitana de São Paulo.

\section{Instrumentos}

Para a coleta de dados foram utilizados três instrumentos, O MBI - Maslach Burnout Inventory, o PVS - Personal Views Survey e o QSD - Questionário Sociodemográfico. O instrumento denominado MBI (Maslach \& Jackson, 1981/1986), construído para verificar a presença de burnout, é composto de 22 questões, auto-aplicáveis, desenvolvidas em torno de três eixos, cansaço emocional (CE) com nove itens, despersonalização (DP) com cinco itens e realização pessoal (RP) com oito itens. As respostas dos itens são: $0=$ nunca, $1=$ uma vez ao ano ou menos, $2=$ uma vez ao mês ou menos, $3=$ algumas vezes ao mês, $4=$ uma vez por semana, $5=$ algumas vezes por semana, $6=$ todos os dias, numa escala tipo Likert. A pontuação total do questionário é o resultado da soma de todos os pontos das freqüências respondidas nos três eixos ou dimensões do construto. Os índices de confiabilidade foram estimados, em sua forma original, mediante o coeficiente alfa de Cronbach numa amostra de 1.316 casos (USA), na qual se obtiveram os seguintes resultados: 0.90 em CE, 0.79 em DP e 0.71 em RP. Na presente pesquisa utilizou-se a forma cujas normas foram extraídas de estudos realizados no Brasil pelo NEPASB - Núcleo de Estudos e Pesquisas sobre burnout, sediado na Universidade Estadual de Maringá, cujos índices de confiabilidade foram: 0,83 para CE, 0,56 para DP e 0,76 para RP, numa amostra de 595 sujeitos.

O segundo instrumento utilizado foi o PVS, para verificar a qualidade de personalidade resistente ao estresse (Kobasa, Maddi \& Khan, 1982). O questionário consta de 50 itens, cujas respostas vão de 0 a 3 (sendo 0 = "totalmente falso" e 3 = "totalmente verdadeiro"); os itens avaliam as três dimensões do construto de personalidade resistente: compromisso, controle e desafio. A escala de compromisso - CP está constituída por um total de 16 itens, a escala de controle - CT está constituída por 17 questões e a escala de desafio - DS está constituída por 17 questões. A pontuação é obtida através de cada uma das escalas e uma pontuação total 
refere-se à personalidade resistente ou hardiness.

As pontuações altas em cada uma das escalas e na globalidade do questionário indicam maior personalidade resistente e maior controle, compromisso e desafio, respectivamente. Os níveis de consistência interna encontrados para todas as escalas foram de 0.90 e de 0.70 para cada uma das dimensões. A confrabilidade medida foi teste-reteste para todo o questionário, com 0.60, no período de duas semanas. Moreno et al. (2000) informam que a adaptação espanhola (que serviu de base para a tradução do questionário utilizado no presente estudo) demonstrou possuir índices psicométricos muito semelhantes aos originais. O Questionário Sociodemográfico foi elaborado exclusivamente para este estudo e trata-se de um conjunto de 15 perguntas fechadas, de múltipla escolha ou de completamento, que abrangem esferas diferentes da vida do sujeito, como segue: identificação (sexo, situação conjugal, idade, escolaridade), tempo de serviço, carga horária e condições pessoais (férias, lazer, sono, medicamentos que toma).

\section{Procedimento}

Os três instrumentos foram aplicados coletivamente, em dois grupos de duas APAEs da grande São Paulo e na presença de um dos pesquisadores. Antes de iniciar a aplicação dos instrumentos os participantes eram informados sobre a pesquisa e esclarecidos de que as informações obtidas eram confidenciais, sendo então solicitado para que assinassem o Termo de Consentimento Livre e Esclarecido. A aplicação dos instrumentos teve a duração de 30 minutos.

\section{Resultados}

Em relação a gênero, escolaridade e situação conjugal apurou-se que $89,3 \%$ da amostra eram do sexo feminino; 48,2\% eram solteiros e 67,8 \% cursaram nível superior. A faixa etária dos participantes variou de 19 anos a 54 anos, apresentando a média de 36 anos e 5 meses, e $71,7 \%$ se encontram concentrados na faixa etária de 21 a 30 anos. Do total da amostra, 52 (92,9\%) tinham entre 21 e 40 anos, apenas $10 \%$ se identificam como efetivamente especializados na educação especial e 8 professores (14\%) tinham apenas o segundo grau completo. Interessante ressaltar que dos 6 homens que participaram da pesquisa, 5 possuíam nível superior e 1 apresentava especialização na área. Tal dado merece atenção, pois esta área, a do Magistério, que parece estar historicamente mais identificada com a figura feminina, mostra-se permeável à migração do professor do sexo masculino e, ainda mais, com formação acadêmica superior, em quase sua totalidade.

Tabela 1 - Distribuição da freqüência de burnout e hardiness entre os participantes

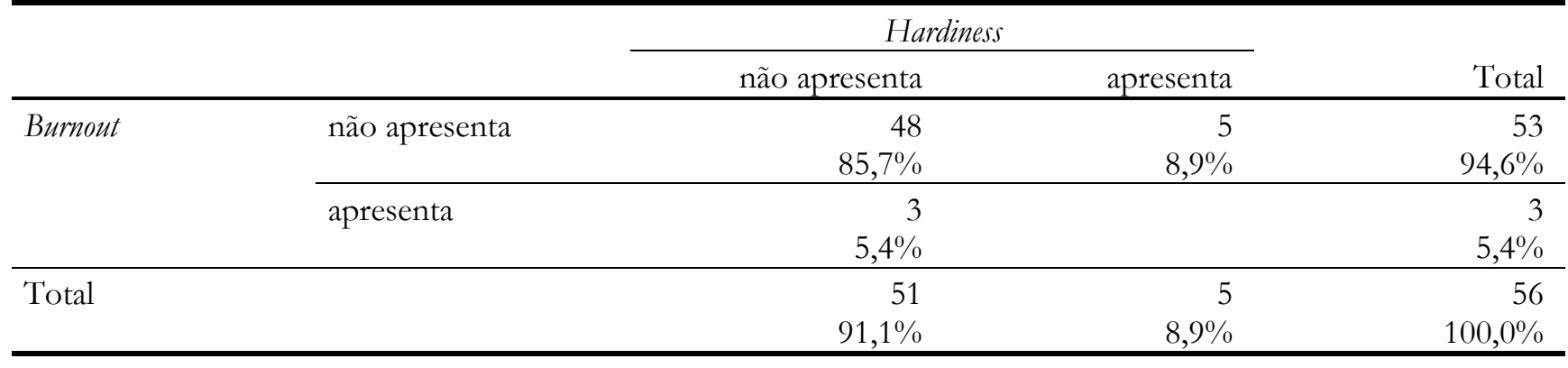

Dos participantes que compuseram a amostra, 8,9\% (5 professores) apresentaram hardiness (pontuação alta nas dimensões de Compromisso, Controle e Desafio) e 3, ou seja, 5,4\% apresentaram burnout (pontuação elevada nas dimensões Cansaço Emocional e Despersona- lização e baixa na Realização Pessoal), conforme apresenta a Tabela 1. Os três participantes que apresentaram burnout eram do sexo feminino, enquanto dos participantes que apresentaram hardiness, 1 era do sexo masculino e 4 do sexo feminino, conforme Tabela 2. 
Tabela 2 - Relação entre sexo, burnout e hardiness

\begin{tabular}{|c|c|c|c|c|c|}
\hline & & & \multicolumn{2}{|c|}{ Burnout } & \multirow[b]{2}{*}{ Total } \\
\hline & & & não apresentam & apresentam & \\
\hline \multirow[t]{6}{*}{ Masculino } & Hardiness & não & 5 & & 5 \\
\hline & & apresentam & $83,3 \%$ & & $83,3 \%$ \\
\hline & & apresentam & 1 & & 1 \\
\hline & & & $16,7 \%$ & & $16,7 \%$ \\
\hline & Total & & 6 & & 6 \\
\hline & & & $100,0 \%$ & & $100,0 \%$ \\
\hline \multirow[t]{6}{*}{ Feminino } & Hardiness & não & 43 & 3 & 46 \\
\hline & & apresentam & $86,0 \%$ & $6,0 \%$ & $92,0 \%$ \\
\hline & & apresentam & 4 & & 4 \\
\hline & & & $8,0 \%$ & & $8,0 \%$ \\
\hline & Total & & 47 & 3 & 50 \\
\hline & & & $94,0 \%$ & $6,0 \%$ & $100,0 \%$ \\
\hline
\end{tabular}

Os participantes que apresentaram burnout estavam compreendidos na faixa de 23 a 26 anos, enquanto os que apresentaram hardiness estavam distribuídos na faixa dos 19 aos 34 anos. Dentre os que apresentaram burnout, 100\% trabalhavam 20 horas semanais; dos participantes que apresentaram hardiness, 1 trabalhava 12 horas semanais; 3 trabalhavam 20 horas semanais e 1 trabalhava 36 horas semanais.

Dos participantes, 8,9\% (5 sujeitos) revelaram propensão ao burnout, conforme Tabela 3. Tratavam-se de sujeitos que mostraram alterações significativas em duas dimensões do MBI, sem, contudo, desenvolver a síndrome.

Tabela 3 - Distribuição de freqüências e porcentagens referentes à propensão ao burnout em relação à hardiness (n=56)

\begin{tabular}{|c|c|c|c|c|}
\hline & & \multicolumn{2}{|c|}{ Hardiness } & \multirow[b]{2}{*}{ Total } \\
\hline & & não apresenta & apresenta & \\
\hline \multirow[t]{4}{*}{ Propensão } & não apresenta & 47 & 4 & 51 \\
\hline & & $83,9 \%$ & $7,1 \%$ & $91,1 \%$ \\
\hline & apresenta & 4 & 1 & 5 \\
\hline & & $7,1 \%$ & $1,8 \%$ & $8,9 \%$ \\
\hline \multirow[t]{2}{*}{ Total } & & 51 & 5 & 56 \\
\hline & & $91,1 \%$ & $8,9 \%$ & $100,0 \%$ \\
\hline
\end{tabular}

$\mathrm{Na}$ análise estatística descritiva dos resultados dos instrumentos, quanto à dimensão do MBI - Maslach Burnout Inventoy, Cansaço Emocional - CE, observou-se uma pontuação de mínimo de 7 e máximo de 51, média de 22,71, mediana de 21, moda de 25 e desvio padrão de 10,80. Esses dados mostram uma distribuição da curva normal e assimétrica positiva, conforme a Figura 1.

Também na dimensão do MBI, Despersonalização - DP, verificou-se pontuação mínima de 0 e máxima de 25 , obtendo-se uma média de 5,16, mediana de 3 , moda 0 (zero) e desvio padrão de 6,18. Assim, observou-se uma forte distribuição assimétrica positiva, como apresenta a Figura 2.

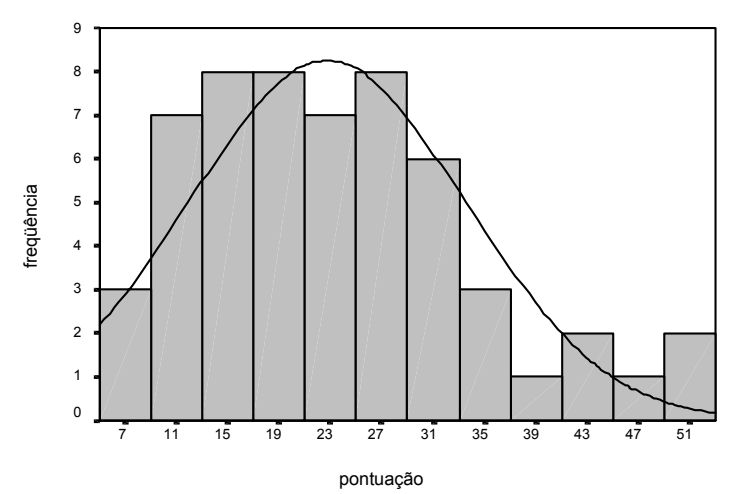

Figura 1 - Cansaço Emocional - CE ( $\mathrm{n}=56)$ 


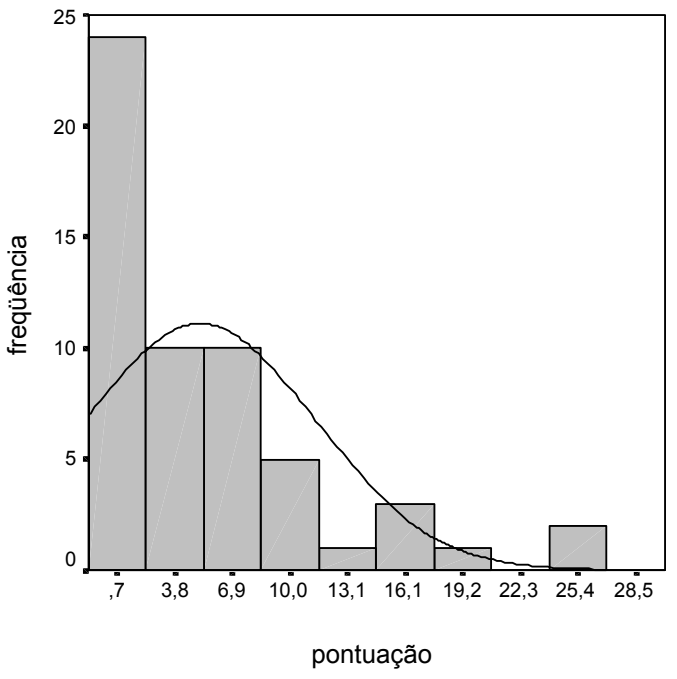

Figura 2 - Despersonalização - DP ( $\mathrm{n}=56$ )

Na dimensão do MBI - Realização Pessoal $\mathrm{RP}$, verificou-se uma pontuação mínima de 17 e máxima de 47, com uma média de 38,35, mediana de 40, moda de 42 e desvio padrão de 6,16. Em decorrência, apresentou uma forte distribuição assimétrica negativa, como mostra a Figura 3.

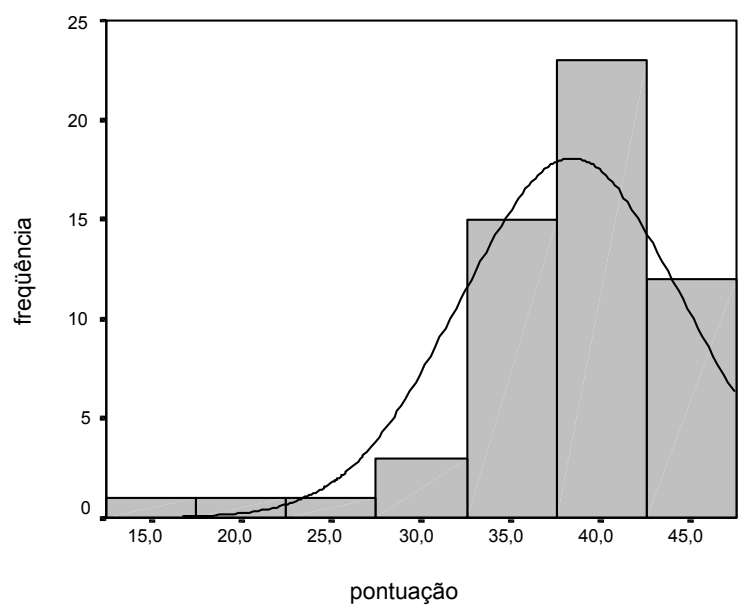

Figura 3 - Realização Pessoal - RP ( $n=56)$

Realizando a mesma análise descritiva estatística do outro instrumento, o Personal Views Survey PVS, verificou-se que a dimensão Compromisso (CP) mostrou pontuações de no mínimo 9 e no máximo 34, com uma média de 16,19, mediana de 14, moda de 12 e desvio padrão de 5,47. Dessa forma, ficou caracterizada uma curva assimétrica positiva, conforme mostra a Figura 4.

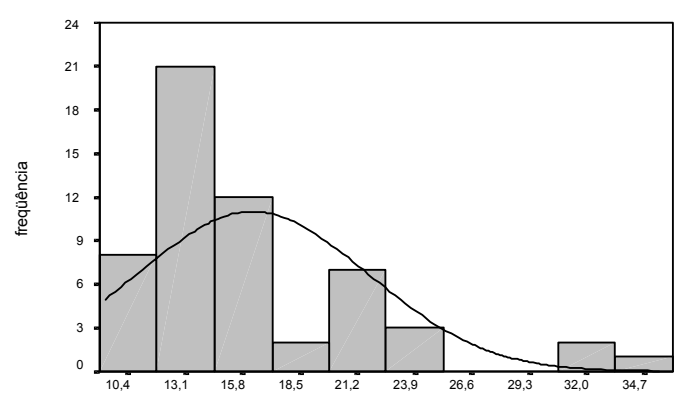

Figura 4- compromisso - Lentuaçăo

Ao proceder à análise da dimensão do PVS, Controle - CT, encontrou-se pontuação mínima de 5 e máxima de 40 , com uma média de 23 , mediana de 22 , moda de 22 e desvio padrão de 6,38. Assim, a curva normal desta amostra é simétrica, conforme Figura 5.

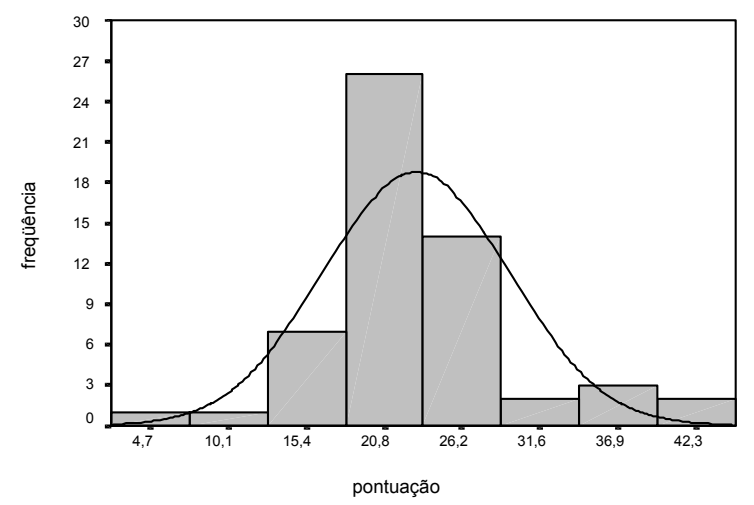

Figura 5 - Controle - CT $(n=56)$

Na dimensão do PVS, Desafio - DS, apuraramse pontuações mínimas de 11 e máximas de 44 pontos, com uma média de 25,42 , mediana de 25 , moda de 25 e desvio padrão de 6,57. Esses dados indicam que a curva normal desta amostra apresenta-se simétrica, conforme Figura 6.

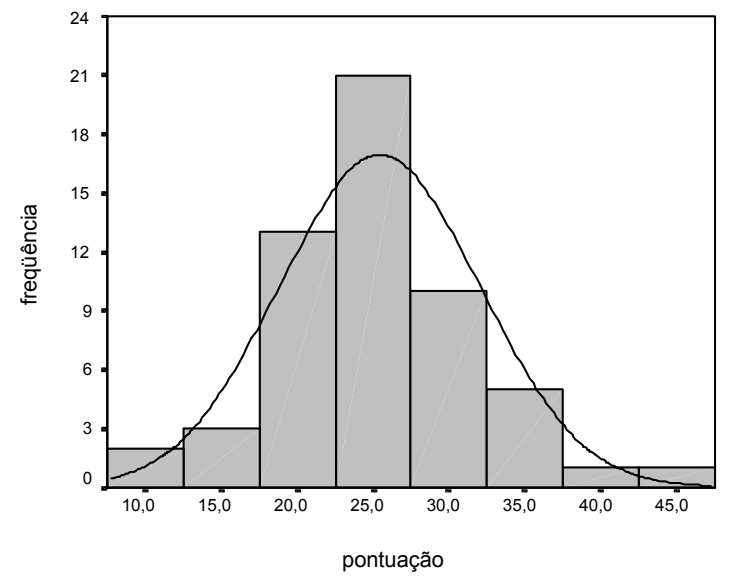

Figura 6 - Desafio DS $(\mathrm{n}=56)$ 
Realizada a análise de correlação para apurar o grau de inter-relação entre as variáveis nas dimensões dos dois instrumentos, MBI - Maslach Burnout Inventory e PVS - Personal Views Survey, verificou-se que nesta amostra os coeficientes de correlação entre a dimensão
Controle - CT e a dimensão Realização Pessoal - RP foram os que apresentaram um grau limítrofe de significância $\mathrm{p}=0,057$. As outras dimensões correlacionadas apresentaram baixo índice de significância, conforme Tabela 4.

Tabela 4 - Coeficientes de correlação e nível de significância entre as dimensões da escala MBI - Maslach Burnout Inventory e PVS - Personal Views Survey $(\mathrm{n}=56)$

\begin{tabular}{lcccc}
\hline & & Compromisso & Controle & Desafio \\
\hline Cansaço Emocional & $\mathrm{r}$ & 0,188 & $-0,094$ & 0,025 \\
& $\mathrm{p}$ & 0,165 & 0,489 & 0,856 \\
Despersonalização & $\mathrm{r}$ & 0,129 & $-0,144$ & $-0,108$ \\
& $\mathrm{p}$ & 0,343 & 0,288 & 0,430 \\
\multirow{2}{*}{ Realização Pessoal } & $\mathrm{r}$ & $-0,054$ & 0,256 & 0,108 \\
& $\mathrm{p}$ & 0,694 & 0,057 & 0,429 \\
\hline
\end{tabular}

\section{Discussão}

Por envolverem muito contato humano, as profissões orientadas para a assistência, para o cuidar, como as ocupações nas áreas da saúde e educação, são chamadas hoje de "alto contato" e têm sido tomadas como exemplo sempre que se deseja falar de desgaste profissional. Schaufeli e Van Mierlo (1994) definitivamente afirmam que o burnout é o maior problema da educação atualmente. Os professores de qualquer nível são, de fato, objeto de inúmeras pesquisas (Byrne, 1994; Carlotto, 2002; Codo \& Menezes, 1999; Moreno et al., 1999), porque o exercício profissional docente tem sido tradicionalmente associado à presença de fatores estressantes, tanto de ordem institucional e social quanto os advindos da própria natureza e exigências da função; não encontrou-se, porém, nenhuma referência, no Brasil, de estudos sobre o conceito de Kobasa (1979), denominado hardiness ou personalidade resistente. Dessa forma, ao verificar a importância do desgaste profissional em professores, já contemplada em tantas pesquisas nacionais e estrangeiras, decidiu-se contribuir para a extensão desse acervo, ampliando o estudo para a análise de uma possível influência específica da personalidade resistente no processo de enfrentamento ao burnout. Não encontrou-se, igualmente, referência a outro estudo realizado exclusivamente com professores com esta especialidade; foi possível localizar estudo semelhante realizado em Madrid, por Moreno et al. (2002), cuja amostra era composta por 33 docentes em educação especial e 30 docentes de educação primária.

Quando se verifica o quadro sindrômico do burnout, como síndrome plenamente instalada, caracterizada por CE alto, DP alto e RP baixa, temos que 3 sujeitos apresentam-na, o que equivale a 5,4\% da amostra de burnout (Tabela 1), todos do sexo feminino, entre os mais jovens, ou seja, de 23 a 26 anos, cuja carga horária semanal é de 20 horas, e tempo de serviço de 1 a 6 anos no mesmo emprego, todos dormindo de 7 a 8 horas diariamente.

Em relação ao que se chamará neste estudo de propensão ao burnout (alteração de duas dimensões cansaço emocional alto ou moderado e despersonalização alta ou moderada, presentes no mesmo participante), encontrou-se que 5 deles $(8,9 \%)$ se mostram propensos a desenvolver a síndrome; isto representa que, somados aos 5,4\% de burnout instalado, $14,3 \%$, ou seja, 8 dos 56 professores participantes desta amostra se acham desgastados e em sofrimento originado da sua relação com o ambiente laboral.

Tornou-se difícil encontrar na bibliografia disponível a respeito de pesquisas em educação, com professores de vários níveis, resultados explícitos globais sobre a incidência de burnout nas amostras estudadas. Geralmente encontram-se referências aos perfis a partir das dimensões. Codo e Menezes (1999), pesquisando 39.000 professores da rede pública brasileira, apontam para índices preocupantes: registram que 48,4\% da categoria demonstram estar com pelo menos uma das três dimensões do burnout alterada, estando 25,1\% com alta Exaustão Emocional (CE), 10,7\% com Despersonalização (DP) e 31,9\% da amostra denotam falta de envolvimento com as tarefas do magistério. Quando se considera pelo menos uma das três dimensões nitidamente alterada, verifica-se que 48,4\% dos professores da amostra revelam-se em sofrimento advindo do trabalho, o que caracteriza, de fato, uma categoria desgastada.

Nosso estudo aponta para uma incidência de $5,4 \%$ (3 participantes), índice que se localiza ligeiramente abaixo da média encontrada nas pesquisas 
realizadas com trabalhadores da saúde. Varoli (2002), que pesquisou profissionais de saúde mental, refere que em uma amostra de 115 participantes, 7\% revelavam-se com a síndrome instalada. Araújo (2001), cuja pesquisa abordou 128 profissionais de enfermagem, encontrou índice de 9,4\% (12 participantes) e Benevides et al. (1999) encontraram 10,6\% de uma amostra de médicos com a síndrome desenvolvida.

Relacionando-se o sexo dos participantes com a presença da síndrome de burnout, verifica-se que o fato de estar instalada totalmente em mulheres, nesta amostra, coincide com dados de Bianchini-Matamoros (1997), que refere ser a população feminina a mais acometida pelo burnout. Importante destacar que o fato de os mais jovens, assim como aqueles que há menos tempo trabalham na instituição, estarem mais acometidos pelo burnout, também é respaldado por outros autores, que afirmam serem os mais velhos provavelmente dotados de certas estratégias eficazes de enfrentamento, desenvolvidas ao longo dos anos e que os tornam menos vulneráveis aos fatores estressantes, adquirindo maior domínio sobre sua prática e mais autoconfiança (Abalo \& Roger, 1998).

Embora Maslach e Leiter (1999) apontem para a relação entre carga de trabalho e desgaste físico e mental, neste estudo verificou-se que os mais acometidos não são os que têm carga horária maior; ao contrário, são os que trabalham meio período, num total de 20 horas semanais. Presumivelmente, outras fontes de estresse às quais o professor esteja exposto permanentemente sejam responsáveis pelo desencadeamento do burnout.

Nosso estudo pretendeu verificar se os portadores de hardiness são mais protegidos contra situações estressantes, como afirmam Gil-Monte e Peiró (1997), Kobasa (1979), Moreno et al. (2000), Sciacchitano et al. (2001). Dos resultados que encontramos, 8,9\% (5 participantes) apresentam-se como portadores de personalidade resistente, sendo 4 deles do sexo feminino. Localizam-se ao longo das faixas etárias, desde 19 anos a 34 anos, como também por diversas faixas de carga horária (12, 20 e 36 horas semanais). Interessante notar que todos os que apresentam hardiness trabalham na instituição de 1 a 3 anos apenas.

Em nossa amostra, 5 apresentaram hardiness e outros 3 participantes apresentaram burnout (Tabela 2). Tais resultados parecem confirmar os enunciados teóricos sobre a relação excludente entre os dois construtos, conforme apontam Moreno et al. (2000), Gil-Monte et al. (1997) e Sciacchitano et al. (2001). Realmente não se configura quadro de burnout nos professores estudados, que provam possuir hardiness. Verifica-se, inclusive, um caso de propensão ao burnout, mas não desenvolvido, possivelmente por ser um sujeito portador de hardiness (Tabela 4). Os resultados encontrados parecem confirmar o modelo de Personalidade Resistente que prevê sua influência modeladora nos processos de estresse.

$\mathrm{Na}$ análise descritiva dos instrumentos, observouse que no MBI a tendência dos professores estudados era pouca para Cansaço Emocional, pouca para Despersonalização e muita para baixa Realização Pessoal. No PVS encontramos poucos professores com tendência a Compromisso, a maioria com Controle e também com Desafio.

$\mathrm{Na}$ correlação das dimensões dos instrumentos, observou-se que o MBI apresentou correlação significativa entre suas dimensões, sendo positiva em relação a Cansaço Emocional e Despersonalização (CE e DP) (r $=0,612)$, negativa em relação a Realização Pessoal e Cansaço Emocional (RP e CE) ( $\mathrm{r}=-0,50)$ e também negativa entre Realização Pessoal e Despersonalização (RP e DP) ( $r=-0,558)$. Já no PVS, encontrou-se boa correlação entre suas três dimensões, e todas positivas, como segue: Compromisso $(\mathrm{CP})$ em relação a Controle (CT) $(r=0,507)$; Compromisso (CP) em relação a Desafio (DS) $(r=0,674)$ e Desafio (DS) em relação a Controle (CT) $(\mathrm{r}=0,595)$, todas com nível de significância $(\mathrm{p}<$ 0,01), dados corroborados pelos estudos de Moreno et al. (2000), em Madrid, com coeficientes de correlação positivos entre Compromisso, Controle e Desafio.

Em relação aos dois instrumentos (MBI e PVS), encontrou-se uma correlação altamente significativa entre as dimensões Controle (CT) e baixa Realização Pessoal (RP) ( $\mathrm{r}=0,256 ; \mathrm{p}<0,057)$. Moreno et al. (2000) também afirma a especial associação que encontrou entre a dimensão Controle (CT) e baixa Realização Pessoal.

\section{Conclusões}

A discussão dos resultados que acabamos de expor podem subsidiar algumas considerações conclusivas sobre os assuntos aqui abordados. De fato, neste estudo, verificou-se que cinco professores apresentaram-se como portadores de hardiness e não apresentaram burnout. Esta constatação permite afirmar que, nesta amostra, hardiness pode ser vista como um indicador negativo de burnout.

Ao se estudarem aspectos de validade dos instrumentos, confirma-se a validade do MBI, pois os dados aqui encontrados demonstraram uma relação direta entre Cansaço Emocional (CE) e Despersonalização (DP) e uma relação inversa entre essas duas e baixa Realização Pessoal. Verificou-se, também, correlação significativa entre a dimensão do PVS Controle (CT) e a dimensão de baixa Realização Pessoal (RP) medida pelo MBI, dado este que indica que quanto maior o Controle, mais alta é a Realização Pessoal.

Importante registrar que trabalhamos, neste estudo, com instrumentos criados para possibilitar a identificação e verificação de incidência tanto do desgaste profissional, burnout, como das variáveis de personalidade, 
hardiness, daqueles que a ele resistem ou o enfrentam. Verificamos a validade concorrente dos dois instrumentos, porém não prosseguimos o estudo para fazer a prova de precisão dos mesmos. Recomendamos novos estudos que visem complementar o presente e venham a aprimorar os conhecimentos aqui registrados.

\section{Referências}

Abalo, J. G. \& Roger, M. C. (1998). ALAPSA. "Burnout: una amenaza a los equipos de salud". Conferencia apresentada en la II Jornada de Actualizações em Psicologia de la Salud, Habana, Cuba: Associacion Latinoamericana de Psicologia de la Salud.

Alchieri, J. C. (2002). Questões Introdutórias sobre medida em Psicologia. Disponível na Internet: Site http://www.unisinos.br. Acesso: em 20/3/02.

Araújo, V. L. N. (2001). Sindrome de Burnout e saúde geral em trabalhadores da saúde. (Dissertação de Mestrado). São Bernardo do Campo: Universidade Metodista de São Paulo - UMESP.

Benevides-Pereira, A. M. T. (2002). Burnout: quando o trabalho ameaça o bem-estar do trabalhador. São Paulo: Casa do Psicólogo.

Benevides-Pereira, A. M. T., Souza, A. H. G., Lima, D. S., Pasqualito, G. A., Hartmann, J. M., Pinto, M. E. B. \& Lara, P. M. S. (1999). A Síndrome de Burnout em médicos de um hospital público e de um privado no Paraná - Brasil, resumo de Simpósium Ibérico do Sindroma de Burnout. Lisboa.

Bianchini-Matamoros， M. (1997). El sindrome del Burnout en personal profesional de la salude. Medicina Legal de Costa Rica, 13-14(2), 1-2.

Byrne, B. M. (1994). Burnout: Testing for the validity, replication, and invariance of causal structure across elementary, intermediate, and secundary teachers. American Educational Research Joumal, 31, 645-676.

Capitão, C. G. (1998). Saúde mental: sofrimento e trabalho. Revista de Psicologia Hospitalar, ano 8, 15(2).

Carlotto, M. S. (2002). A síndrome de burnout e o trabalho docente. Psicologia em Estudo, 7(1), 21-29.

Casullo, M. M. (1997). Perspectivas actuales en la avaluación psicológica. Anais do VII Encontro Nacional sobre Testes Psicológicos. Porto Alegre: PUC-RS.

Codo, W. \& Menezes, I. V. (1999). O que é burnout? Em Wanderlei Codo (Org.). Educação: carinho e trabalho. (pp. 237-254). Rio de Janeiro: Ed. Vozes.

Dejours, C. (1997). A loucura do trabalho - estudo de Psicopatologia do trabalho. São Paulo: Cortez.

Farber, B. A. (1991). Crisis in education. Stress and burnout in the american teacher. San Francisco: Jossey-Bass Inc.

Fráguas. R. J. \& Figueiró, J. A. B. (Orgs.). (2001) Depressões secundárias: peculiaridades da depressão no contexto médico e não-psiquiátrico. Em Depressões em medicina interna e em outras condições médicas: depressões secundárias. Rio de Janeiro: Atheneu, p. 3.

Freudenberger, H. J. (1974). Staff burn-out. Journal of Social Issues, 30(1), 159-165.

Gil-Monte, P. \& Peiró, J. M. (1997). Desgaste psíquico em el trabajo: el sindrome de quemar-se. Espanha: Ediciones Síntesis.

Guglielmi, R. S. \& Tatrow, K. (1998). Occupational stress, burnout, and health in teachers: A methodological and theoretical analysis. Review of Educational Research, 68(1), 61-69.

Kobasa, S. C. (1979). Stressful life events, personality and health: An inquiry into Hardiness. Journal of Personality and Social Psychology, 37(1), 137-155.

Kobasa, S. C., Maddi, S. R. \& Khan, S. (1982). Hardiness and health. A prospective study. Journal of Personality and Social Psychology, 42(2), 168-177.

Maslach, C. \& Jackson, S. (1981/1986). The Maslach Burnout Inventory. Palo Alto, California: Consulting Psychologists Press.

Maslach, C. \& Leiter, M. P. (1999). Trabalho: fonte de prazer ou desgaste? Campinas: Papirus.

Moreno, J. B. \& Olivier, H. (1993). El MBI como escala de estrés en profissiones asistenciales: Adaptación y nuevos versiones. Aportaciones a la evaluación psicológica. Barcelona.

Moreno, J. B., Garrosa, H. E. \& Gonzalez, G. J. L. (1999). Burnout docente, sentido de la coherencia y salud percibida. Coherencia y burnout. Revista de Psicopatologia y Psicologia Clinica, 3(4), 163-180.

Moreno, J. B., Garrosa, H. E. \& Gonzalez, G. J. L (2000). Personalidad resistente, burnout y salud. Escritos de Psicologia, 4, 64-77.

Moreno, J. B., Garrosa, H. E., Gálvez, M., Gonzalez, G. J. L. \& Benevides, A. M. T. (2002). A avaliação de burnout em professores. Comparação de instrumentos: CBPR e MBI-ED. Psicologia em Estudo, 8(1), 11-19.

Pasquali, L. (Org.). (1999). Instrumento psicológico: manual prático de elaboração. LabPAM/IBAPP, p. 32.

Pasquali, L. (Org.) (2001). Técnicas de exame psicológico: fundamentos das técnicas de exame psicológico. LabPAM, PROAV. São Paulo: Casa do Psicólogo, p. 39.

Peñacoba, C. \& Moreno, J. B. (1998). El concepto de personalidad resistente: consideraciones teóricas y repercusiones prácticas. Boletim de Psicologia, 58, 61-96.

Psico-USF, v. 9, n. 1, p. 19-29, Jan./Jun. 2004 
Schaufeli, W. B. \& Van Mierlo, H. (1994). Burnout among dutch teachers: an MBI validity study. Educational and Psychological Measurement, 54(3), 803-812.

Sciacchitano, M., Goldstein, M. B. \& DiPlacido, J. (2001). Stress, burnout and hardiness. RTs. Radiol. Technol., 72(4), 321-328.

Seisdedos, N. (1997). Manual del MBI. Madrid: Departamento de ID TEA Ediciones S. A.

Sisto, F. S., Codenotti, M., Costa, C. A. J. \& Nascimento, C. N. T. (1979). Testes Psicológicos no
Brasil: o que medem realmente. Educacão e Sociedade, 2. São Paulo: Cortez \& Moraes, p. 153.

Varoli, I. (2002). O sofrimento dos que tratam: Burnout em profissionais de saúde mental na região do $A B C$. (Dissertação de Mestrado). São Bernardo do Campo: Universidade Metodista de São Paulo - UMESP.

Recebido em abril de 2004 Reformulado em maio de 2004 Aprovado em maio de 2004

Sobre os autores:

Sandra Cristina Mallar é psicóloga, mestre em Psicologia pela Universidade São Francisco e professora de Avaliação Psicológica no Centro Universitário Santo André (UNIA).

Cláudio Garcia Capitão é psicólogo, doutor em Educação pela UNICAMP, com pós-doutorado em psicologia clínica pela PUC-SP, professor do Curso de Graduação e do Programa de Estudos Pós-Graduados em Psicologia da Universidade São Francisco. 


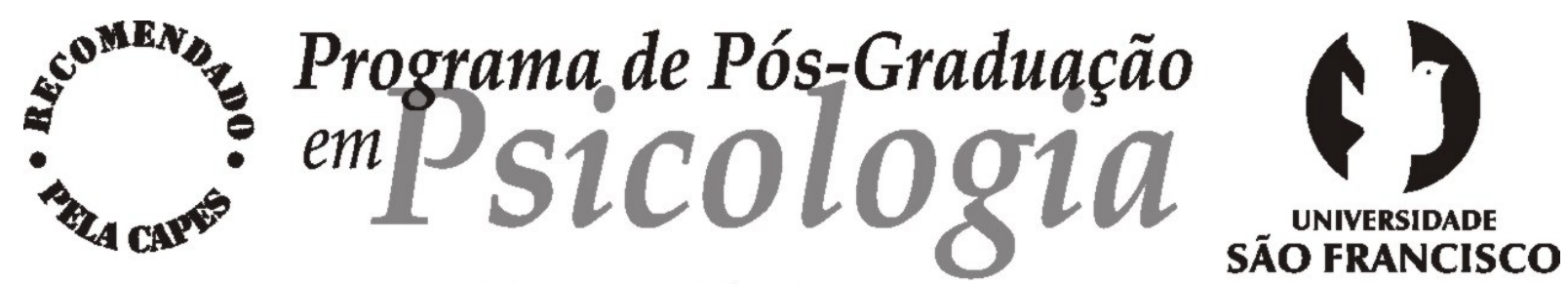

UAACH - Unidade Acadêmica da Área de Ciências Humanas e Sociais Câmpus de Itatiba

\begin{abstract}
Objetivos
O Programa de Mestrado e Doutorado em Psicologia tem como objetivo (a) formar pesquisadores em nível de Mestrado para que estes possam atuar em serviços e instituições públicas e particulares, a fim de desenvolver atividades de pesquisa, consultorias, assessorias e prestação de serviços que envolvam avaliação psicológica e psicoeducacional; (b) proporcionar experiências que contribuam para a formação de docentes do ensino superior com conhecimento especializado na área de avaliação e medidas; (c) propiciar experiências e discussões teóricas envolvendo construção, aprimoramento e utilização de instrumentos e procedimentos de avaliação psicológica e psicoeducacional em situações específicas e (d) prestar serviços, assessorias e consultorias visando à inserção da universidade na comunidade e contribuindo para o desenvolvimento de serviços de excelência em avaliação psicológica e psicoeducacional na região.
\end{abstract}

\title{
Destinado a
}

Profissionais graduados em Psicologia e áreas correlatas

Comissão de Pós-Graduação em Psicologia (CPG)

Profa. Dra. Ana Paula Porto Noronha (Presidente)

Profa. Dra. Anna Elisa de Villemor Amaral

Profa. Dra. Maria Cristina Rodrigues Azevedo Joly

Prof. Dr. Cláudio Garcia Capitão (Suplente)

\section{Linhas de Pesquisa}

1. Construção, Validação e Padronização de Instrumentos de Medida

Corpo Docente: Profa. Dra. Ana Paula Porto Noronha

Profa. Dra. Claudette Maria Medeiros Vendramini

Prof. Dr. Fermino Fernandes Sisto

Prof. Dr. Ricardo Primi

2. Avaliação Psicológica em Contextos da Saúde Mental

Corpo Docente: Profa. Dra. Alessandra Gotuzo Seabra Capovilla

Profa. Dra. Anna Elisa de Villemor Amaral

Prof. Dr. Claúdio Garcia Capitão

Prof. Dr. Makilim Nunes Baptista

\section{Avaliação em Psicologia Educacional}

Corpo Docente: Profa. Dra. Acácia Aparecida Angeli dos Santos Prof. Dr. Fermino Fernandes Sisto

Profa. Dra. Maria Cristina Rodrigues Azevedo Joly

Prof. Dr. Ricardo Primi 